\title{
Enhanced MDM2 oncoprotein expression in soft tissue sarcoma: several possible regulatory mechanisms
}

\author{
RAPHAEL E. POLLOCK, ${ }^{1,2}$ AIQUING LANG, ${ }^{1}$ ADEL K. EL-NAGGAR, ${ }^{3}$ \\ ROBERT RADINSKY ${ }^{4} \&$ MIEN CHIE HUNG ${ }^{2}$ \\ Departments of ${ }^{1}$ Surgical Oncology, ${ }^{2}$ Tumor Biology, ${ }^{3}$ Pathology and ${ }^{4}$ Cell Biology, MD Anderson Cancer Center, \\ University of Texas, USA
}

\begin{abstract}
Purpose. MDM2 is an oncogene whose protein product may promote tumorigenesis by blocking wild-type p53 tumor suppressor mediated $\mathrm{G}_{0} / \mathrm{G}_{1}$ cell cycle arrest, thereby inhibiting repair of damaged DNA prior to cell division. While $M D M 2$ DNA amplification is frequently observed in human sarcoma, the mechanisms linking this amplification to MDM2 oncoprotein over-production as well as its functional significance have not been well characterized in patients with soft tissue sarcoma.

Methods. A tissue bank of resected soft tissue sarcomas and autologous normal tissues was assembled; all specimens were snap frozen within $15 \mathrm{~min}$ of resection. DNA and RNA were extracted from tissues using isoamyl alcohol and phenol chloroform extraction methods, respectively; cell lysates were prepared using PBSTDS lysis buffer. DNA and mRNA were confirmed as being non-degraded and were then examined for MDM2 DNA amplification (Southern blots) and mRNA over-expression (Northern blots) using actin (DNA) and glyceraldehyde-3-phosphate dehydrogenase (mRNA) as loading controls. The MDM2 protein was examined on Western blots using the MDM2-specific monoclonal antibody IF2 (Oncogene Science, Inc). The presence of p53 DNA and expression of p53 mRNA was examined by rehybridizing the Southern and Northern filters using a p53-specific cDNA probe.

Results. Soft tissue sarcomas and autologous normal tissues were screened for MDM2 DNA amplification, which was detected in 10 of 30 tumors screened. After screening, there was sufficient biomaterials from six specimens for subsequent Northern and Western analysis to see whether MDM2 gene amplification correlated with over-expression of MDM2 mRNA and MDM2 protein. In addition, we examined whether other mechanisms may lead to over-expression of the MDM2 oncoprotein. Several possible mechanisms of MDM2 oncoprotein over-expression were identified. These most commonly included MDM2 DNA amplification, MDM2 mRNA over-expression and MDM2 oncoprotein over-expression. However, some soft tissue sarcoma patient specimens had no evidence of MDM2 mRNA over-expression yet had MDM2 oncoprotein over-production in the tumor relative to autologous normal tissue, implying possible post-transcriptional regulation. Of functional relevance, MDM2 oncoprotein over-production by tumors was associated with large decreases in the percentage of cells in the $G_{0} / G_{1}$ cell cycle interface compared with autologous normal tissue cells. Discussion. It is likely that there are multiple mechanisms underlying human soft tissue sarcoma MDM2 oncoprotein over-production. Consequently, strategies that decrease MDM2 over-production, such as transcriptional repression to inhibit MDM2 promoter activity or RNA antisense approaches, may ultimately offer the best therapeutic efficacy.
\end{abstract}

Key words: soft tissue sarcoma, MDM2, oncogene amplification.

\section{Introduction}

The MDM2 oncogene codes for a $90-\mathrm{kDa}$ protein may be involved in regulation of tumor proliferation via suppression of wild-type (wt) p53 mediated $\mathrm{G}_{1}$ cell cycle checkpoint control. ${ }^{1,2}$ MDM2 can overcome wt p53 suppression of transformed cell growth, ${ }^{3}$ most likely by forming a complex with wt p $53^{4}$ and thereby concealing the wt p53 activation domain. ${ }^{5}$ Experimentally induced DNA damage increases levels of MDM 2 mRNA in cells expressing wt p $53 ;^{6}$ wt p53 may transcriptionally activate the MDM 2 gene. ${ }^{7,8}$ These interactions suggest an autoregulatory feedback loop in which wt p53 protein regulates the $M D M 2$ gene at the transcriptional level and MDM 2 protein regulates wt p53 protein at the activity level. ${ }^{9,10}$ This autoregulatory network as elucidated in the above cell line experimentation suggests that the coordinate presence of mutated p53 and MDM2 would be redundant in suppressing $\mathrm{G} 1$ 
checkpoint control. ${ }^{9}$ Consistent with this, most initial tumor tissue observations have failed to detect MDM2 gene amplification in the presence of mutated p53 gene. ${ }^{9}$

MDM2 oncoprotein inactivation of tumor suppressor gene function may also alternatively involve physical and functional interaction with RB, the protein product of the retinoblastoma tumour suppressor gene, thereby inhibiting RB-mediated tumor growth regulation. ${ }^{11}$ Moreover, the MDM2 oncoprotein may not only release a tumor proliferative control by blocking p53 and RB, but may also positively augment tumor proliferation by stimulating the cell cycle $S$-phase inducing transcription factors E2F1/DP1. ${ }^{12}$ Studies in MDM2-deficient mice have provided important insights regarding the interaction of MDM2 and p53 in vivo. ${ }^{13,14}$ MDM2 null mice are not viable; however, MDM2 null lethality is avoidable in mice that are also p53 null, suggesting a critical in vivo role of MDM2 as a negative regulator of p53 function in normal development. ${ }^{14}$

Mechanisms underlying the production of MDM2 protein in tumor tissue have not yet been fully characterized. However, MDM2 gene amplification has been described in a variety of tumors including carcinoma of the breast, ${ }^{15}$ glioma, ${ }^{16-18}$ pancreatic adenocarcinoma, ${ }^{19,20}$ osteosarcoma, ${ }^{21}$ urothelial carcinomas, ${ }^{22,23}$ some leukemias, ${ }^{24}$ Hodgkin's ${ }^{25}$ and non-Hodgkin's lymphomas, ${ }^{26}$ several gynecologic malignancies, ${ }^{27}$ neuroblastoma ${ }^{28}$ and germ cell tumors, ${ }^{29}$ and as an especially frequent finding in soft tissue sarcoma. ${ }^{30}$

In light of these considerations, we sought to analyze MDM2 in soft tissue sarcoma and autologous normal tissue at the DNA, RNA and protein levels to delineate possible mechanisms underlying sarcoma over-production of MDM2 oncoprotein. Our studies suggest several patterns of regulation including $M D M 2$ gene amplification, possible transcriptional and post-transcriptional regulation, and coordinate presence of $M D M 2$ gene amplification with possible p53 gene mutation, a finding not anticipated by the MDM2-p53 autoregulatory loop hypothesis.

\section{Patients and methods}

Tissue acquisition and preservation

Soft tissue sarcoma, autologous normal skeletal muscle resected as part of the surgical specimens and autologous peripheral blood lymphocytes were retrieved, fast-frozen in liquid nitrogen, and stored in a $-140^{\circ} \mathrm{C}$ freezer for subsequent usage. These tissues were acquired as part of a clinical research protocol approved by the University of Texas MD Anderson Cancer Center Surveillance Committee (Institutional Review Board).

\section{$D N A$ analysis}

High molecular weight DNA from normal and tumor samples was extracted by proteinase $\mathrm{K}$ digestion and phenol/chloroform extraction. A $2.2-\mathrm{kb}$ human MDM 2 fragment and a $1.8-\mathrm{kb}$ human p53 fragment were used as probes in Southern blot analyses. A $\beta$-actin probe was used as an internal loading control. Both the human MDM2 and p53 plasmids were provided as a kind gift by $\mathrm{Dr} B$. Vogelstein. For the Southern blot analysis, $20 \mu \mathrm{g}$ of genomic DNA were digested with EcoRI restriction endonuclease overnight and then electrophoretically separated on $0.8 \%$ agarose gel and blotted to nylon membranes. The membranes were prehybridized with $1 \times$ Church buffer at $65^{\circ} \mathrm{C}$ for $1 \mathrm{~h}$ and hybridized with the MDM 2 DNA probe that had been labeled at $65^{\circ} \mathrm{C}$ overnight with $\left[{ }^{32} \mathrm{P}\right] \mathrm{dCTP}$ using a random primer DNA labeling kit (Boeringer Mannheim Corp., Indianapolis, IN, USA). Membranes were then washed and subjected to autoradiography at $-80^{\circ} \mathrm{C}$ for $4-20 \mathrm{~h}$ using intensifying screens. The same membranes were then washed twice with $0.1 \%$ sodium dodecyl sulfide followed by $0.1 \mathrm{X} \mathrm{SSC}$ at $100^{\circ} \mathrm{C}$ for $20 \mathrm{~min}$ for each wash and then rehybridized with the human p53 and $\beta$-actin probes.

\section{$m R N A$ analysis}

Total cellular RNA was extracted directly from snap frozen tumor specimens using a guanidinium thiocyanate-hot phenol method as described previously. $^{31}$ For Northern blot analyses, Poly $\left(\mathrm{A}^{+}\right)$ RNA was prepared by oligo(dT)-cellulose chromatography, fractionated on $1 \%$ denaturing formaldehyde-agarose gels, electrotransferred at $0.6 \mathrm{~A}$ to a GeneScreen nylon membrane (DuPont Co., Boston, MA, USA) and UV cross-linked with $120000 \mu \mathrm{J} \mathrm{cm}^{-2}$ using a UV Stratalinker 1800 (Stratagene, La Jolla, CA, USA). Filters were washed two or three times at $60^{\circ} \mathrm{C}$ with $30 \mathrm{mM}$ $\mathrm{NaCl}-3 \mathrm{mM}$ sodium citrate ( $\mathrm{pH} \mathrm{7.2)-0.1 \%}$ $\mathrm{NaDodSO}_{4}$ (w/v). A glyceraldehyde-3-phosphate dehydrogenase (GAPDH) probe was used as a loading control. The cDNA probes used were a $2.2-\mathrm{kb}$ restriction endonuclease fragment from the plasmid corresponding to the full length $M D M 2$ human cDNA.

\section{Cellular protein analysis}

Western blot analyses of autologous sarcoma and normal tissues were performed as previously described. ${ }^{32}$ The nitrocellulose membrane was blocked with $2 \%$ non-fat milk in TPBS buffer (0.05\% Tween-20 in phosphate-buffered salup (PBS) buffer) for $1 \mathrm{~h}$ and then incubated with $1 \mu \mathrm{g} \mathrm{m} l^{-1}$ of MDM2-specific monoclonal antibody $\mathrm{Ab}$ IF2 (Oncogene Science, Inc., Uniondale, NY, USA). 


\section{Southern}

Normal Tumor
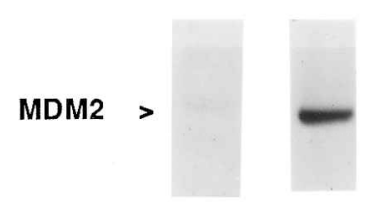

p53
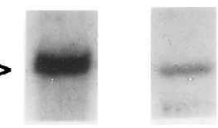

Actin >

\section{Northern}

Tumor
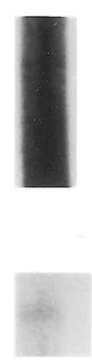

\section{Western}

Normal Tumor

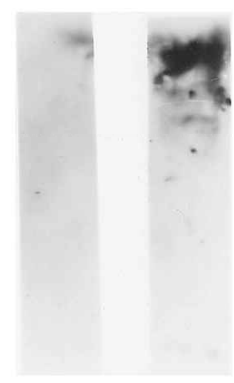

GAPDH >

Fig. 1. Standard pattern of MDM2 oncoprotein over-production. DNA analysis demonstrates MDM2 gene amplification. There is MDM2 mRNA expression and increased MDM2 oncoprotein production relative to autologous normal tissue.

\section{Southern}

Normal Tumor
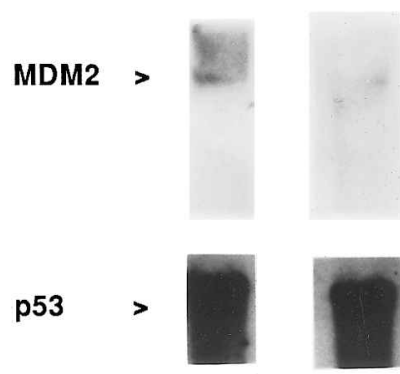

Actin
Northern

Normal Tumor
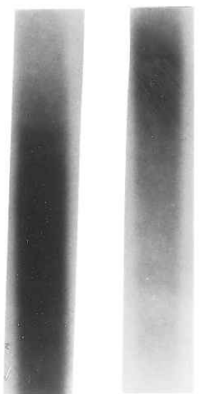

GAPDH >
Western

Normal Tumor

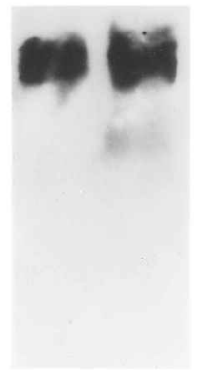

Fig. 2. Lack of MDM2 oncoprotein over-production. There is no detectable MDM2 gene amplification or $m R N A$ over-expression. MDM 2 oncoprotein production is equivalent in sarcoma and autologous normal tissue.

Southern

Normal Tumor

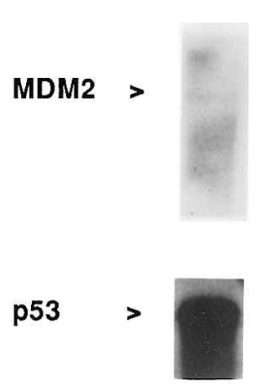

Actin
Northern

Normal Tumor

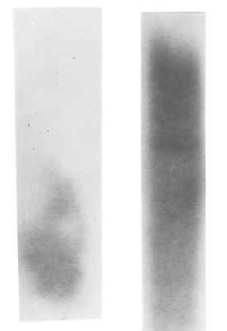

\section{Western}

Normal Tumor

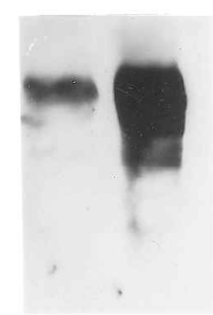

GAPDH >

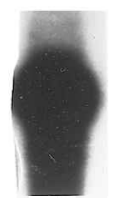

Fig. 3. MDM2 oncoprotein over-production: possible post-transcriptional regulation. While there is clear MDM2 DNA amplification in the tumor compared with autologous normal tissue, MDM $2 \mathrm{mRNA}$ does not appear to be over-expressed in the tumor. However, there is obvious increased tumor MDM 2 oncoprotein over-production. 


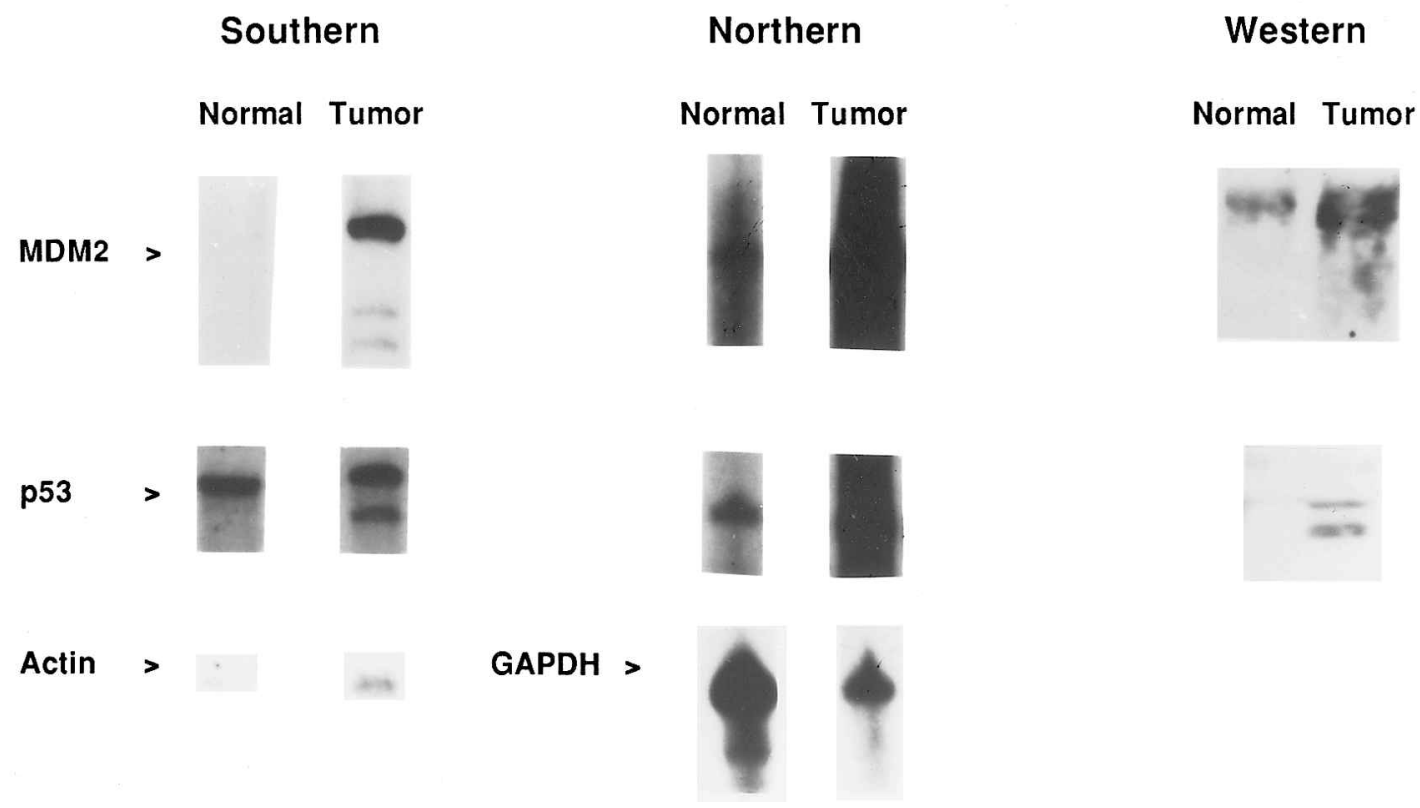

Fig. 4. MDM2 oncoprotein over-production: possible p53 mutations. The Southern analysis demonstrates MDM2 DNA amplification in tumor as well as a possible coexisting p53 mutation. Over-expressed $m R N A$ and tumor over-production of MDM 2 oncoprotein are also observable.

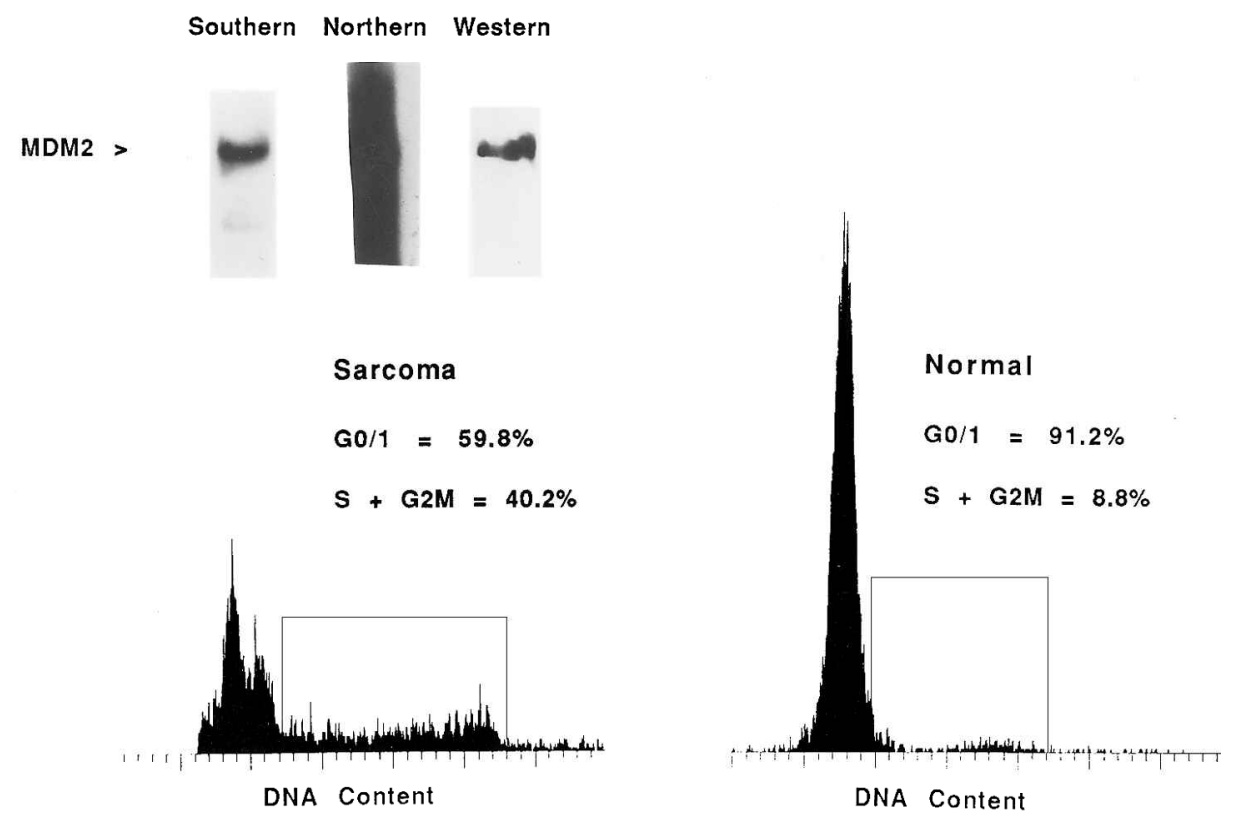

Fig. 5. Dysregulated cell-cycle kinetics in a sarcoma with MDM2 oncoprotein over-production. The standard pattern of MDM 2 oncoprotein over-production is observed as per Fig. 1. The percentage of cells in the $S+G_{2} M$ phase is increased more than four-fold in the sarcoma relative to the autologous normal tissue.

\section{Flow cytometry}

Disaggregated cells were adjusted to $1.0 \times 10^{6}$ cells/ $\mathrm{ml}$ for flow cytometric analysis of DNA content in fresh tissues. A cytospin preparation was evaluated for preparation quality and nuclear integrity. Cells were subsequently stained with acridine orange using the standard two-step method. Ploidy status was defined by the DNA index, which represents the ratio of the relative $\mathrm{G}_{0} / \mathrm{G}_{1}$ diploid peak. Neardiploid (hypodiploid or hyperdiploid) DNA was determined after mixing a test sample with lymphocyte controls.

\section{Results}

An initial screen of 30 resected soft tissue sarcomas identified 10 tumors with MDM2 amplication at the DNA level. In several patients (predominantly liposarcoma) there was sufficient sarcoma as well as autologous normal tissue to support a more extensive analysis at the DNA, mRNA and cellular protein levels. Figure 1 is representative of the typical pattern of MDM2 protein over-production in sarcoma relative to that in autologous normal tissue: $M D M 2$ DNA amplification in tumor (Southern blot), abundant MDM2 mRNA (over) expression in 
the tumor (Northern blot) and MDM2 protein over-expression by sarcoma (Western blot) compared to the autologous normal tissue. In contrast, Fig. 2 is representative of the more typical pattern observed at the initial tumor screening: no sarcoma MDM 2 DNA amplification, and equivalent levels of MDM2 mRNA expression with comparable levels of MDM2 protein production in both the sarcoma and autologous normal tissues.

Figure 3 illustrates an alternative possible mechanism of MDM2 protein over-production by tumor. While there is relative sarcoma $M D M 2$ DNA amplification, there is minimal if any detectable MDM2 mRNA over-expression in the tumor. However, there is markedly increased MDM2 protein production in the tumor relative to that in autologous normal tissue, implying a possible $M D M 2$ post-transcriptional level of regulatory control.

MDM2 may interact with p53 in an autoregulatory loop control process such that p53 protein regulates the $M D M 2$ gene at the level of transcription, and MDM 2 protein regulates the p53 protein at the level of its activity. ${ }^{9}$ Because this hypothesized feedback loop regulates both the activity of the p53 protein as well as the expression of the $M D M 2$ gene, it would be redundant for a tumor to contain both MDM 2 gene amplification and p53 gene mutations. However, Fig. 4 illustrates the possibility that these two alterations may coexist within a single sarcoma. As depicted, there is $M D M 2$ DNA amplification in the sarcoma relative to that seen in autologous normal tissue. In addition, there is a possible p53 mutation detectable in the sarcoma that is not detected in the normal tissue. Both MDM2 and p53 mRNA transcripts were present, and there was relative MDM2 and p53 protein over-production in the sarcoma tissues compared to the autologous control tissues.

Lastly, we analyzed the potential functional significance of MDM2 protein over-production given that $M D M 2$ blockade of wt p53 leads to loss of $\mathrm{G}_{0} / \mathrm{G}_{1}$ cell cycle arrest and a concomitant increase in the percentage of cells in the $S+G_{2} M$ phase of the cell cycle. Figure 5 depicts flow cytometry histograms for a representative sarcoma and autologous normal tissue where there was concomitant sarcoma MDM2 DNA amplification and MDM2 protein over-production. Cell cycle dysregulation is suggested in that the normal tissue percentage of cells in the $G_{0} / G_{1}$ cell cycle phase was $91.2 \%$ and the $\mathrm{S}+\mathrm{G}_{2} \mathrm{M}$ percentage was $8.8 \%$, whereas the comparable percentages in the sarcoma were $59.8 \%$ and $40.2 \%$, respectively.

\section{Discussion}

While MDM 2 gene amplification appears to be a relatively common event in soft tissue sarcoma and several other solid malignancies, the spectrum of involvement apparently does not include medul- loblastoma, ${ }^{33}$ melanoma, ${ }^{34}$ Ewing's sarcoma, ${ }^{35}$ cervical carcinoma, ${ }^{36}$ myelodysplastic syndromes, ${ }^{37}$ Wilms' tumor ${ }^{38}$ and esophageal carcinoma. ${ }^{39}$ However, many studies have considered only MDM2 gene amplifications (Southern analysis) or, alternatively, MDM2 protein production. This strategy may miss possible translational or post-transcriptional regulatory mechanisms; therefore, the spectrum of tumor involvement may perhaps be broader than has been initially described.

In keeping with this possibility, Landers et al. recently described experiments using two different choriocarcinoma cell lines in which elevated MDM2 protein levels were not associated with gene amplification or over-expression of MDM2 mRNA. ${ }^{40}$ Instead, a post-transcriptional regulatory mechanism was shown to be responsible for enhanced translation. Olson et al. demonstrated four other MDM2 protein forms (p85, p76, p74 and p58-p57) in addition to p90 that were detected in a spontaneously transformed BALB/c mouse 3 T3 cell line using monoclonal and polyclonal antibodies generated against murine and human MDM2 proteins. ${ }^{41}$ It is possible that these alternative proteins could have arisen from various spliced mRNA forms of the MDM 2 gene or by post-translational MDM2 protein alterations. ${ }^{41}$

Working with breast carcinoma cell lines, Sheikh et al. demonstrated that the high constitutive MDM2 mRNA levels observed in estrogen receptor positive cells was the result of differential regulation of the MDM2 gene at the transcriptional and/or post-transcriptional level. ${ }^{15}$ Similar post-transcriptional regulatory mechanisms were also identified in studies involving breast carcinoma cell lines conducted by Gudas et al. ${ }^{42}$ However, to date, MDM2 post-transcriptional regulation has not been analyzed in soft tissue sarcoma, perhaps because of the relative rarity of the disease and the difficulties in extracting mRNA from sarcoma tissues. ${ }^{30,43}$

Several studies have focused on the issue of concomitant MDM 2 gene amplification and p53 gene mutation in soft tissue sarcoma. Leach et al. analyzed 24 soft tissue sarcomas, identifying eight tumors with p53 mutations and a non-overlapping subset of another eight sarcomas with MDM2 gene amplification (DNA analysis). ${ }^{44}$ It was concluded that $\mathrm{p} 53$ and $M D M 2$ genetic alterations were alternative mechanisms for inactivating the same regulatory pathway and that double mutations in both p53 and MDM2 were redundant and provided no selective advantage over mutation in only one of the two genes.

Cordon-Cardo et al. examined a larger selection of soft tissue sarcomas using Southern analysis and immunohistochemical analysis. ${ }^{45}$ Seventy-six of 211 sarcomas had abnormally high levels of MDM2 protein; 56 of these 211 tumors over-expressed p53 proteins. Twenty-two of these 211 sarcomas had abnormally high levels of both p53 and MDM2 
proteins. These 22 patients had significantly impaired survival relative to the other individuals studied. However, these immunohistochemical determinations apparently did not include a direct comparison of $\mathrm{p} 53$ and MDM2 protein status that incorporated autologous normal control tissues. Because of possible differences between autologous normal and sarcoma tissues, as we have detected in the MDM 2 Western analyses here, it is difficult to conclude that the presence of immunohistochemical positive staining for both p53 and MDM2 in the same sarcoma sample means that there is a coexisting double mutation of these respective genes.

In this same analysis, over-expression of either p53 or MDM2 protein on immunohistochemistry did not always correlate with MDM2 gene amplification or p53 gene mutation as determined by DNA analysis. While 11 of 73 sarcomas had $M D M 2$ amplification interpreted as at least 5-35 fold gene copy excess, only six of these 11 tumors had increased MDM 2 protein. In contrast, 17 of 62 sarcomas with increased MDM2 protein lacked detectable $M D M 2$ gene amplification.

These findings suggest that there might be additional MDM2 gene mutations not detected by the Southern analysis, or that the immunohistochemical analysis did not detect the presence of one or another of the alternative MDM2 protein forms. As an additional possibility, post-transcriptional or posttranslational regulation may be operative, as is suggested in Fig. 3, or perhaps MDM2 mRNA levels were under-expressed. These latter possibilities might be resolvable using an MDM2 mRNA analytic strategy.

Alternatively, since $M D M 2$ over-expression is sufficient for inactivation of wt p53 function, the possible double mutation of both p53 and MDM2 genes in the sarcoma depicted in Fig. 4 and the analysis of Cordon-Cardo et al. suggests that there might be a 'gain of function' in the development of sarcoma. Additional studies, possibly utilizing cotransfection strategies, will be required to address this issue.

Florenes et al. examined 68 sarcomas, 26 human sarcoma xenografts and two sarcoma cell lines for MDM 2 amplification and p53 mutations in exons 5, 7 or 8 , as well as p53 and MDM2 mRNA overexpression. ${ }^{46}$ They observed amplification of the MDM 2 gene in 10 tumors, nine of which also had MDM2 mRNA over-expression. However, MDM2 mRNA was also over-expressed in an additional three sarcomas that lacked MDM2 gene amplification. None of the tumors with MDM2 gene amplification had mutations detected in their respective p53 genes. The presence of MDM2 or p53 protein product production was not examined in this study. Taken together, these reports point to the importance of experimental schema that consider MDM2 and p53 status on the DNA, RNA and protein levels in both sarcomas and paired autologous tissues.

Therapeutic strategies to blunt the functional impact of $M D M 2$ gene amplification that leads to over-production of MDM2 oncoprotein will need to account for the possibility of multiple regulatory mechanisms, multiple oncoprotein products, and the yet to be established potential interplay between simultaneous MDM2 gene amplification and p53 gene mutations. Transcriptional regulation, RNA antisense approaches or even augmentation of $\mathrm{wt}$ p53 cell cycle regulatory function in MDM2 amplified tumors may prove to be feasible and of future therapeutic benefit for patients burdened by soft tissue sarcoma.

\section{Acknowledgements}

We would like to acknowledge the excellent secretarial support of Elizabeth B. Hardham. This research was supported by NCI NIH RO 1 CA67802 (REP), NCI NIH R29 CA67952 (RR), the Sid Richardson Foundation (RR) and the NCI NIH Cancer Center Core Grant CA16672.

\section{References}

1 Chen CY, Oliner JD, Zhan Q, et al. Interactions between p53 and MDM2 in a mammalian cell cycle checkpoint pathway. Proc Natl Acad Sci 1994; $91: 2684-8$.

2 Fakharzadeh SS, Trusko SP, George DL. Tumorigenic potential associated with enhanced expression of a gene that is amplified in a mouse tumor. $E M B O f$ $1991 ; 10: 1565-9$.

3 Finlay CA. The mdm-2 oncogene can overcome wildtype p53 suppression of transformed cell growth. Mol Cell Biol 1993; 13:301-6.

4 Barak Y, Oren M. Enhanced binding of a $95 \mathrm{kDa}$ protein to p53 in cells undergoing p53-mediated growth arrest. EMBO f 1992; 11:2115-21.

5 Momand J, Zanbetti GP, Olson DC, et al. The mdm2 oncogene product forms a complex with p 53 protein and inhibits p53-mediated transactivation. Cell 1992; 69: 1237-45.

6 Price BD, Park SJ. DNA damage increases the levels of MDM2 messenger RNA in wt p53 human cells. Cancer Res 1994; 54:896-9.

7 Juven T, Barak Y, Zauberman A, et al. Wild type p53 can mediate sequence-specific transactivation of an internal promoter within the $\mathrm{mdm} 2$ gene. Oncogene 1993; 8:3411-16.

8 Barak Y, Juven T, Haffner R, et al. mdm2 expression is induced by wild type p53 activity. EMBO $f$ 1993; $12: 461-8$.

9 Wu X, Bayle $\mathrm{H}$, Olson $\mathrm{D}$, et al. The p-53-mdm-2 autoregulatory feedback loop. Genes and Dev 1993; $7: 1126-32$.

10 Otto A, Deppert W. Upregulation of mdm-2 expression in meth A tumor cells tolerating wild-type p53. Oncogene 1993; 8:2591-603.

11 Xiao Z, Chen J, Levine AJ, et al. Interaction between the retinoblastoma protein and the oncoprotein MDM2. Nature 1995; 375:694-8.

12 Martin K, Trouche D, Hagemeier C, et al. Stimulation of E2F1/DP1 transcriptional activity by MDM2 oncoprotein. Nature 1995; 375:691-4. 
13 Jones SN, Roe AE, Donehower LA, et al. Rescue of embryonic lethality in Mdm2-deficient mice by absence of p53. Nature 1995; 378:206-8.

14 Montes de Oca Luna R, Wagner DS, Lozano G. Rescue of early embryonic lethality in mdm2-deficient mice by deletion of p53. Nature 1995; 378:203-6.

15 Sheikh MS, Shao Z-M, Hussain A, et al. The p53binding protein MDM2 gene is differentially expressed in human breast carcinoma. Cancer Res 1993; $53: 3226-8$.

16 Reigenberger G, Reifenberger J, Ichimura K, et al. Amplification of multiple genes from chromosomal region 12q13-14 in human malignant gliomas: preliminary mapping of the amplicons shows preferential involvement of CDK4, SAS and MDM2. Cancer Res 1994; $54: 4299-303$.

17 Reigenberger G, Liu L, Ichimura $\mathrm{K}$, et al. Amplification and overexpression of the MDM2 gene in a subset of human malignant gliomas without p53 mutations. Cancer Res 1993; 53:2736-9.

$18 \mathrm{He} \mathrm{J,} \mathrm{Reifenberger} \mathrm{G,} \mathrm{Liu} \mathrm{L,} \mathrm{et} \mathrm{al.} \mathrm{Analysis} \mathrm{of} \mathrm{glioma}$ cell lines for amplification and overexpression of MDM2. Genes Chromosom Cancer 1994; 11:91-6.

19 Ebert M, Yokoyama M, Kobrin MS, et al. Increased MDM2 expression and immunoreactivity in human pancreatic ductal adenocarcinoma. Int f Oncol 1994; $5: 1279-84$.

20 Okita S, Tsutsumi M, Onji M, et al. p53 mutation without allelic loss and absence of $\mathrm{mdm}-2$ amplification in a transplantable hamster pancreatic ductal adenocarcinoma and derived cell lines but not primary ductal adenocarcinomas in hamsters. Mol Carcinogenesis 1995; 13:266-71.

21 Landanyi $\mathrm{M}$, Cha $\mathrm{C}$, Lewis $\mathrm{R}$, et al. MDM2 gene amplification in metastatic osteosarcoma. Cancer Res 1993; 53:16-18.

22 Lianes P, Orlow I, Zhang Z-F, et al. Altered patterns of MDM2 and TP53 expression in human bladder cancer. F Natl Cancer Inst 1994; 86:1325-30.

23 Tomonori $\mathrm{H}$, Kinoshita $\mathrm{H}$, Yamada $\mathrm{H}$, et al. Oncogene amplification in urothelial cancers with p53 gene mutation or MDM2 amplification. I Natl Cancer Inst $1994 ; 86: 1331-5$.

24 Quesnel B, Preudhomme C, Oscier D, et al. Overexpression of the MDM2 gene is found in some cases of hematological malignancies. Br f Hematol 1994; $88: 415-18$

25 Chilosi M, Doglioni C, Menestrina F, et al. Abnormal expression of the p53 binding protein MDM2 in Hodgkin's disease. Blood 1994; 84:4295-300.

26 Finnegan MDM, Goepel JR, Royds J, et al. Elevated levels of MDM-2 and p53 expression are associated with high grade non-Hodgkin's lymphomas. Cancer Letters 1994; 86:215-21.

27 Selter H, Amela-Neuschwander S, Villena-Heinsen C, et al. Antibodies against murine double minute-2 $(\mathrm{mdm} 2)$ in sera of patients with various gynaecological diseases. Cancer Lett 1995; 96:111-15.

28 Corvi R, Savelyeva L, Breit S, et al. Non-syntenic amplification of MDM2 and MYCN in human neuroblastoma. Oncogene 1995; 10:1081-6.

29 Riou G, Barrois M, Prost S, et al. The p53 and mdm-2 genes in human testicular germ-cell tumors. Mol Carcinogenesis 1995; 12:124-31.

30 Oliner JD, Kinzler KW, Meltzer PS, et al. Am- plification of a gene encoding a $\mathrm{p} 53$-associated protein in human sarcomas. Nature 1992; 358:80-6.

31 Radinsky R, Kraemer PM, Raines MA, et al. Amplification and rearrangement of the Kirsten ras oncogene in virus-transformed BALB/c 3T3 cells during malignant tumor progression. Proc Natl Acad Sci USA 1987; 34:5143-7.

32 Pollock RE, Lang A, Luo J, et al. Soft tissue sarcoma metastasis from clonal expansion of p53 mutated tumor cells. Oncogene 1996; 12:2035-9.

33 Adesina AM, Nalbantoglu J, Cavenee WK. p53 gene mutation and mdm2 gene amplification are uncommon in medulloblastoma. Cancer Res 1994; 54:564951.

34 Poremba C, Yandell DW, Metze D, et al. Immunohistochemical detection of p53 in melanomas with rare p53 gene mutations is associated with mdm-2 overexpression. Oncol Res 1995; 7:331-9.

35 Kovar H, Auinger A, Jug G, et al. Narrow spectrum of infrequent p53 mutations and absence of MDM2 amplification in Ewing tumours. Oncogene 1993; $8: 2683-90$.

36 Kessis TD, Slebos RJ, Han SM, et al. p53 gene mutations and MDM2 amplification are uncommon in primary carcinomas of the uterine cervix. $A m \mathcal{F}$ Pathol 1993; 143: 1398-405.

37 Preudhomme C, Quesnei B, Vachee A, et al. Absence of amplification of MDM2 gene, a regulator of p53 function, in myelodysplastic syndromes. Leukemia 1993; $7: 1291-3$.

38 Waber PG, Chen J, Nisen PD. Infrequency of MDM2 gene amplification in pediatric solid tumors and lack of association with p53 mutations in adult squamous cell carcinomas. Cancer Res 1993; 53:6028-30.

39 Esteve A, Lehman T, Jiang W, et al. Correlation of p53 mutations with epidermal growth factor receptor overexpression and absence of $\mathrm{mdm} 2$ amplification in human esophageal carcinomas. Mol Carcinogenesis 1993; 8:306-11.

40 Landers JE, Haines Ds, Strauss JF III, et al. Enhanced translation: a novel mechanism of $\mathrm{mdm} 2$ oncogene overexpression identified in human tumor cells. Oncogene 1994; 9:2745-50.

41 Olson DC, Marechal V, Momand J, et al. Identification and characterization of multiple mdm-2 proteins and mdm-2-p53 proteins. Oncogene 1993; $8: 2353-60$.

42 Gudas JM, Nguyen H, Klein RC, et al. Differential expression of multiple MDM2 messenger RNAs and proteins in normal and tumorigenic breast epithelial cells. Clin Cancer Res 1995; 1:71-80.

43 Oliner JD, Pietenpol JA, Thiagalingam S, et al. Oncoprotein MDM2 conceals the activation domain of tumour suppressor p53. Nature 1993; 362:857-60.

44 Leach FS, Tokino T, Meltzer P, et al. p53 mutation and MDM2 amplification in human soft tissue sarcomas. Cancer Res 1993; 53:2231-4.

45 Cordon-Cardo C, Latres E, Drobnjak M, et al. Molecular abnormalities of $\mathrm{mdm} 2$ and $\mathrm{p} 53$ genes in adult soft tissue sarcomas. Cancer Res 1994; 54:794-9.

46 Florenes VA, Maelandsmo GM, Forus A, et al. MDM2 gene amplification and transcript levels in human sarcomas: relationship to TP53 gene status. $\mathcal{f}$ Natl Cancer Inst 1994; 86:1297-1302. 



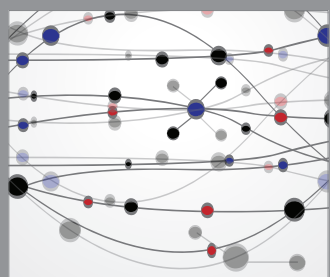

The Scientific World Journal
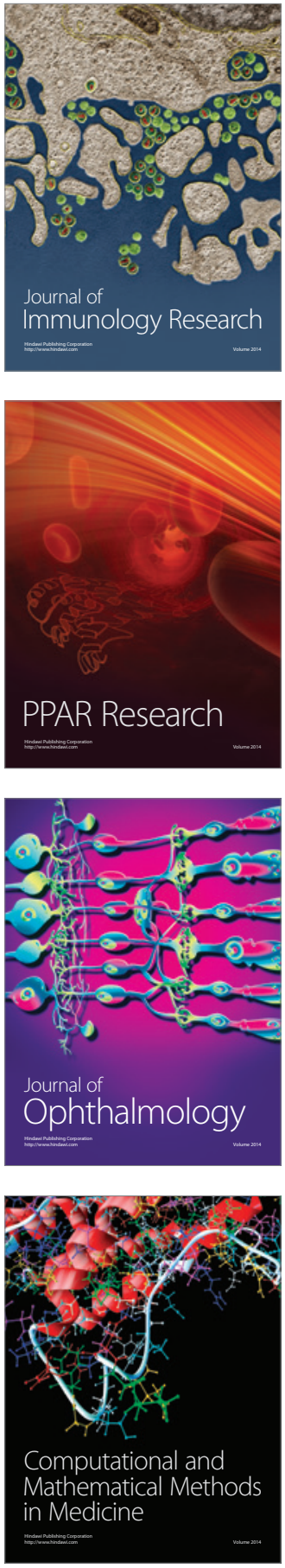

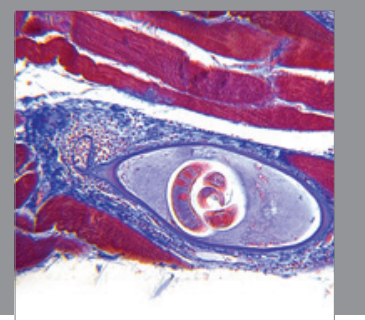

Gastroenterology

Research and Practice
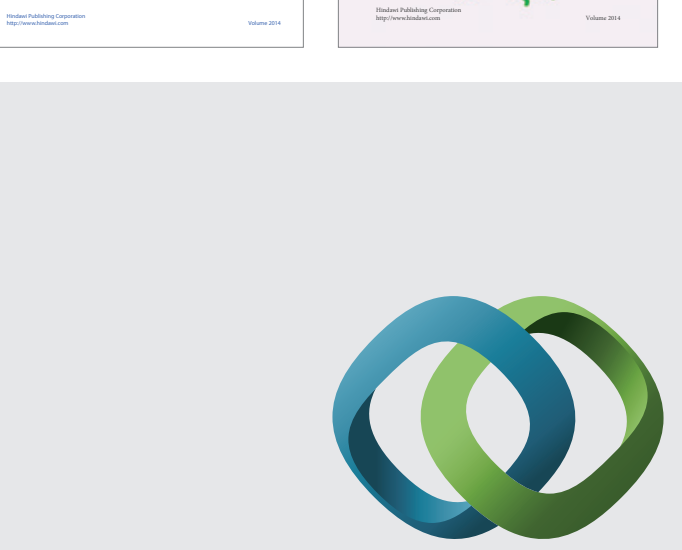

\section{Hindawi}

Submit your manuscripts at

http://www.hindawi.com
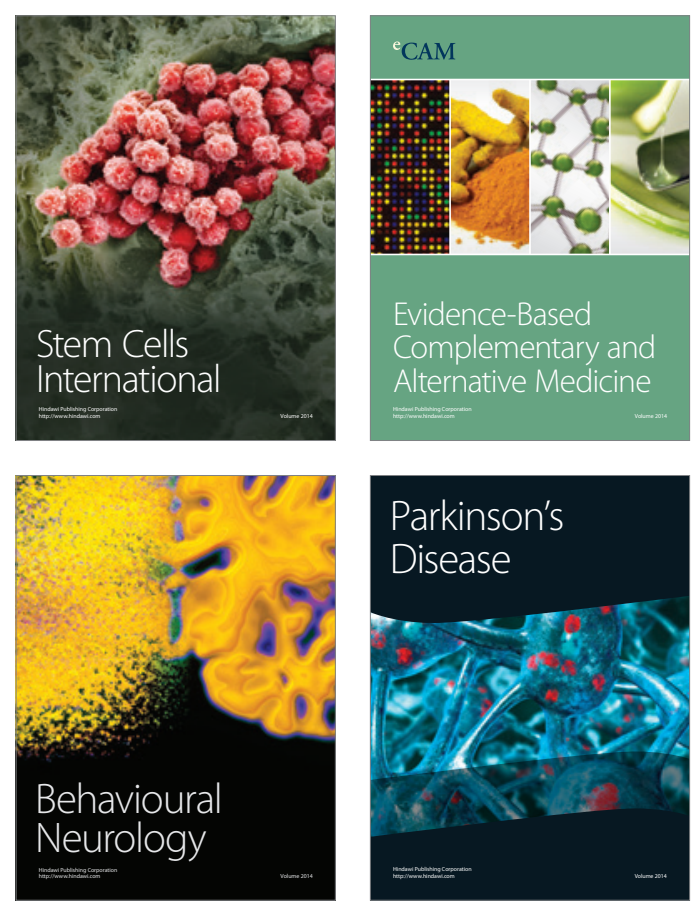

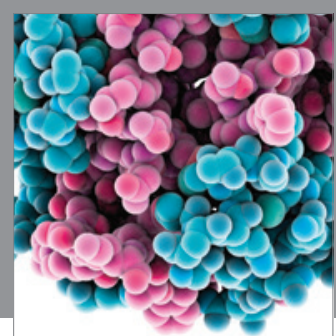

Journal of
Diabetes Research

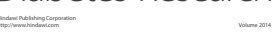

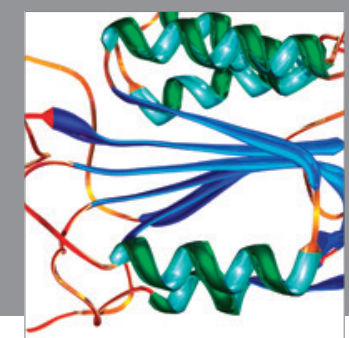

Disease Markers
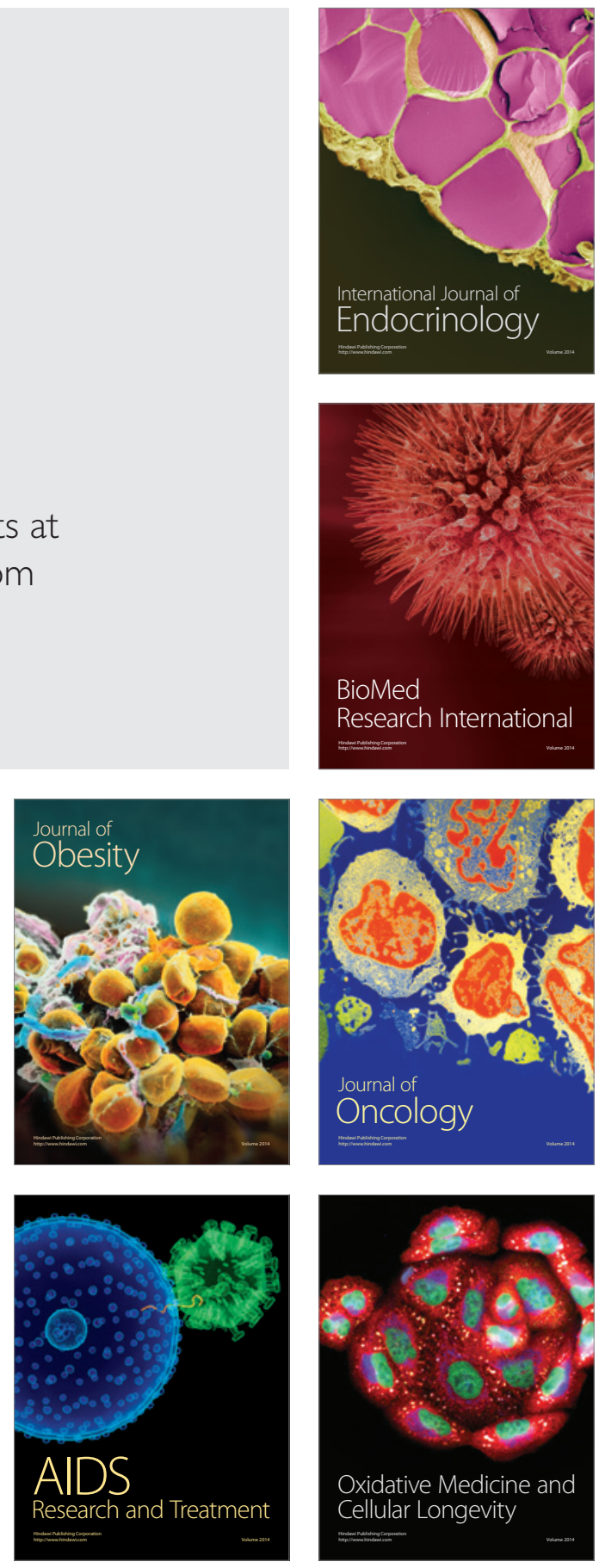